\title{
Cost Optimization of Supply Chain Distribution Model Using Genetic Algorithm
}

\author{
Ratih Nindyasari ${ }^{1}$, Anastasya Latubessy ${ }^{2}$, Alif Catur Murti ${ }^{3}$, Wibowo Hary Sugiharto ${ }^{4}$, \\ Muhammad Malik Hakim ${ }^{5}$ \\ \{ratih.nindyasari@umk.ac.id ${ }^{1}$, anastasya.latubessy@umk.ac.id², alif.catur@umk.ac.id ${ }^{3}$ \} \\ Department of Informatic Engineering, Faculty of Engineering, Universitas Muria Kudus, Kudus - \\ Indonesia $^{12345}$
}

\begin{abstract}
Supply chain is the enterprise network that working together to develop and distributing products to customers. After the products have been produce, they will sending to distributor, and then forward to retailer and finally arrived in customer. Consequently, the role of supply chains distibution are very important. Supply chain enable the product moving from the plant to customers that separated by distance. So it is needed a tools that can solving on supply chain problems in order to minimize distibution cost. In this research, the propose metodology is using genetic algorithm to get result the distribution cost that minimize. The distribution cost has been resulted from this algorithm will be compared with result from TORA. And then we will know if genetic algorithm can be able to solving distribution problems more than optimal.
\end{abstract}

Keywords: supply chain, genetic algorithm, cost optimation, supply chain distribution.

\section{Introduction}

Supply chain is a network of companies that work together to produce and deliver a product to the customer. Examples the raw materials that are deliver from the supplier to the plant. Therefore, the role of distribution and transportation networks is important. This distribution and transport network enables the product to move from the plant to consumer that limited by distance. To solving this conditions, distribution and transportation management will perform some basic functions, and the one of function is to determine the delivery route and the amount of shipping capacity so that it will minimize the total cost of distribution. On the issue of distribution there are two kinds of influential costs. The first is the cost variable, its cost increase along with the increase in the number of products that are transported from source to destination. And the second is a fixed charge or a fixed cost that is not dependent on the amount of products that are transported from the source to destination. Based on the problem of distribution that has been mentioned above it is necessary an application that can produce an optimal solution to solve the problem. Therefore, genetic algorithm is used to determine the most optimal distribution cost. This genetic algorithm $[1][2][3][4][5]$ is aptly used for solving complex optimization problems and difficult to solve by conventional methods.

ICCSET 2018, October 25-26, Kudus, Indonesia

Copyright (C) 2018 EAI

DOI 10.4108/eai.24-10-2018.2280536 


\section{Distribution Problems}

A distribution problem in supply chain discuss about how can a producs deliver start from the plant to suppliers, and then supplier deliver to customer. The aims of distribution problem is to get the optimal cost, so looking for the lower or minimum cost distribution. The characteristic of distribution problems are [6] :

a) The distribution problems have many of supply, source, or plant and demand.

b) The quantity of product, it is the sum of product that will distributed from supply to demand

c) The quantity of product must be suitable with quantity of demand

The distribution model usually can be describe using ilustration in Fig. 1.
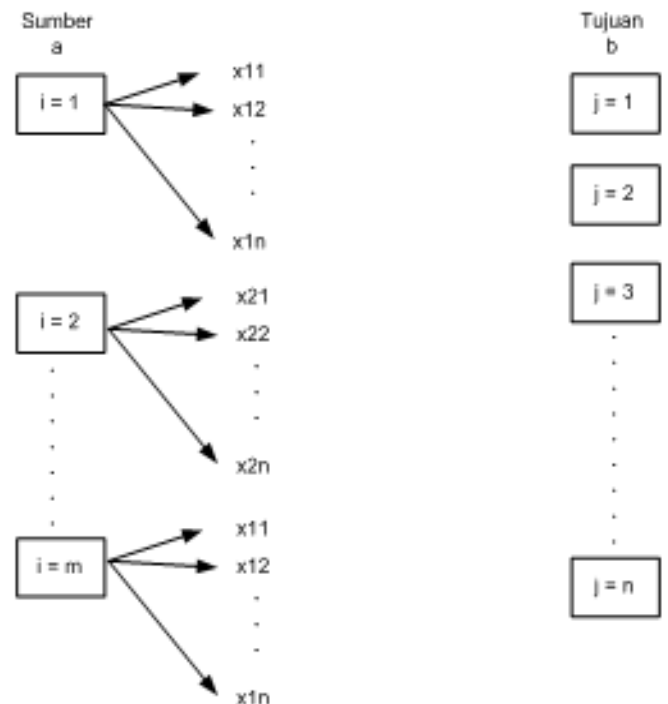

Fig. 1. Ilustration Model of Distribution.

In the Fig. 1 have many $m$ supply and $n$ demand, the figure can explained are :

1. Each of supply have capasity $\left(\mathrm{a}_{\mathrm{i}}\right)$.

2. Each demand need some of product as much as $b_{j}$

3. The sum of unit product that will deliver from supply to demand is $\mathrm{X}_{\mathrm{ij}}$

4. Cost to deliver the unit product from supply to demand is $\mathrm{C}_{\mathrm{ij}}$

Beside on the model from Fig.1, so we can writing the formula of cost distribution is :

$$
\text { Minimize } \mathrm{Z}=\sum_{i=1}^{m} \sum_{j=1}^{n} C i j X i j
$$

Where,

$$
\sum_{i=1}^{n} x_{i j} \leq a_{i}, \quad i=1,2, \ldots, m
$$




$$
\begin{gathered}
\sum_{i=1}^{m} x_{i j} \geq b_{j}, \quad j=1,2, \ldots, n \\
X_{i j} \geq 0 \text { for all } i \text { and } j
\end{gathered}
$$

In the equation 2 show the quantity of product that will deliver not more than the quantity of demand, and the equation 2 explain that the quantity of product that will deliver must be suitable with the demand.

\subsection{Genetic Algorithm}

Genetic algorithm is a technic that using selection mecanism [7]. Based on Darwin's theory of survival, GA have the fittness for optimal value. In the Fig.2 will be explained the work flow on genetic algorithm.

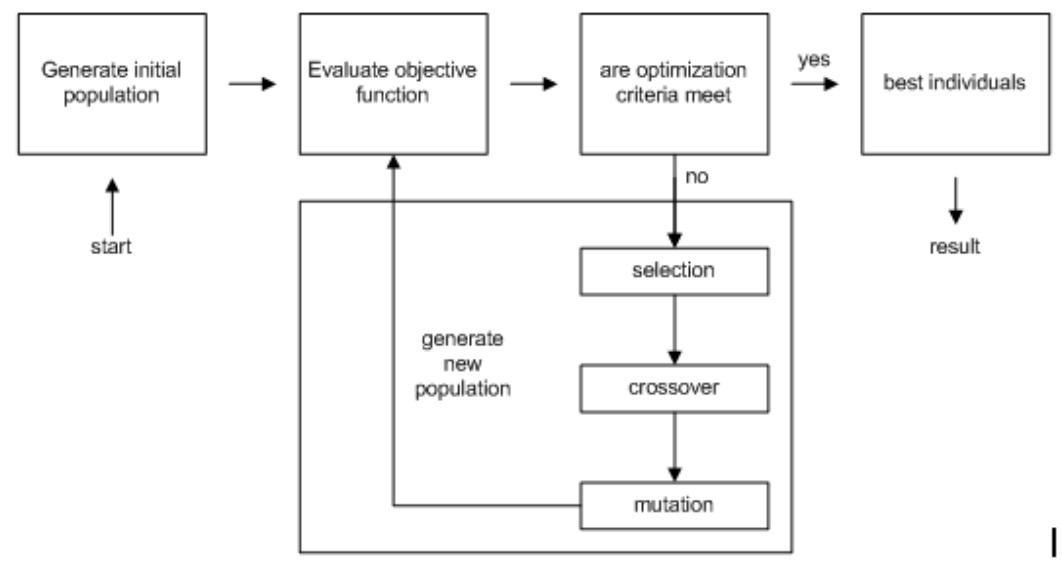

Fig. 2. The work flow of Genetic Algorithm.

In the $1^{\text {st }}$ square on Fig.2, GA will be population cluster randomly. This population will be a candidate of the solution. Each candidate can be tranformation with the biner form. The $2^{\text {nd }}$ square, all candidate will evaluated using objective function and then produce the fitness value. In the $3^{\text {th }}$ square, the population will be compare for get the optimal value. The $4^{\text {th }}$ square is selection process, and next square is crossover, this process is making new individu form previous individu that have characteristics same. 


\section{Metodology}

In this section will be explain about the architecture design of distribution problem and the steps in genetic algorithm.

\subsection{Design of Distribution Problem}

The distribution problem in this research will have two kind of cost. there are the variable cost and the fixed cost. The variable cost is conditional, depend on the quantity of product that will deliver. And the fixed charge have stable characteristic. It is never change althought the quantity of product that will deliver grow up. The model of distribution problems [3][8] can be describe on Fig. 3.

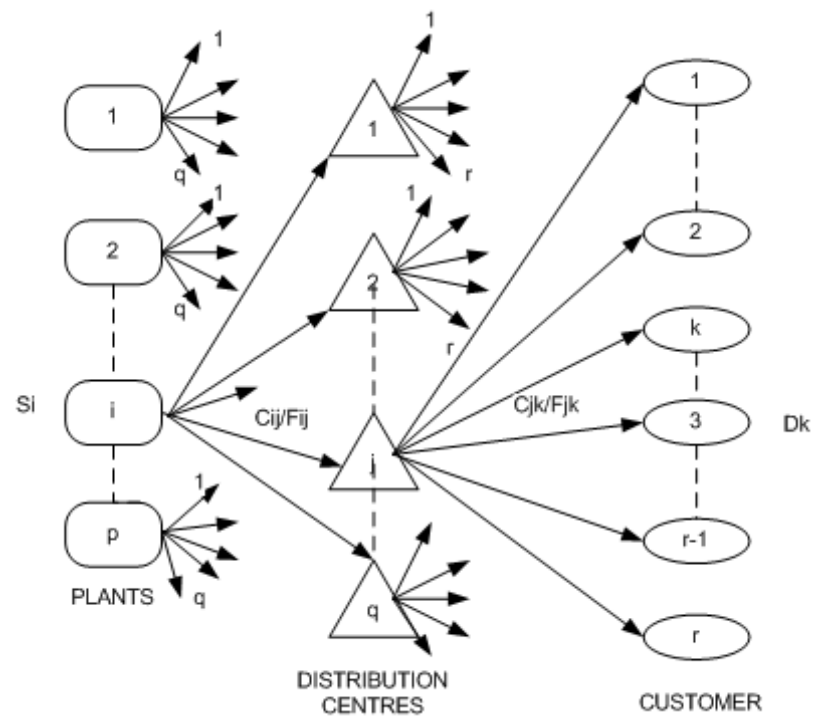

Fig. 3. Model Distribution Problem.

In the model have two kind of level, the first level is start from plant (supplier) to distribution center (warehouse). And the second level have start point from distribution center to customer. Each plant can deliver to any distribution center with cost is $\mathrm{C}_{\mathrm{ij}}$. the cost (Cij) will sum with the fixed charge (Fij). Each distribution center can deliver to any customer with transportation cost is $\mathrm{C}_{\mathrm{jk}}$ and then it is sum with fixed charge $\left(\mathrm{F}_{\mathrm{jk}}\right)$. The plant have some of capacity ( $\mathrm{Si}$ ) dan then distribution center have value of capacity it is called Dk. The distribution problem in this research can calculate with mathematic model in equation 5 .

$$
\operatorname{Minimize} \mathrm{Z}=\sum_{i=1}^{p} \sum_{j=1}^{q}\left(C_{i j} X_{i j}+F_{i j} \delta_{i j}\right)+\left(C_{j k} X_{j k}+F_{j k} \delta_{j k}\right)
$$


Where :

$$
\begin{gathered}
\sum_{j=1}^{q} X_{i j} \leq S_{i} \quad(\forall i, i=1 \text { to } p) \\
\sum_{j=1}^{q} X_{j k}=D_{k}(\forall k, k=1 \text { to } r) \\
X_{i j} \geq 0, \text { and integer } \\
X_{j k} \geq 0, \text { and integer }
\end{gathered}
$$

Table 1. Notation or Input Variable.

\begin{tabular}{lll}
\hline No & Variable/ Notation & Information \\
\hline 1. & $P$ & Number of plant \\
2. & $Q$ & Number of distribution center \\
3. & $R$ & Number of customer \\
4. & $S i$ & The capacity of each plant \\
5. & Dk & Number of demand for each customer \\
6. & Cij & $\begin{array}{l}\text { Cost to deliver form plant } i \text { to distribution } \\
\text { center } j\end{array}$ \\
7. & Fij & Fixed charge from plant $i$ to distribution center \\
& & $j$ \\
8. & Cjk & Cost to deliver from distribution center $j$ to \\
& & customer $k$ \\
9. & Fjk & Fixed charge form distribution center $j$ to \\
& & customer $k$ \\
10. & JumlahGenerasi & Number of generation \\
11. & JumlahKrom & Number of chromosome \\
12. & p_cross & Probability of crossover \\
13. & p_mut & Probability of mutation \\
\hline
\end{tabular}

\subsection{The Work Flow of Algorithm}

In this section, will explained about the architecture desain of genetic algorithm to solve distribution problem. The steps in this algorithm are : 
a. Input module

in this step will using data input on Table 1. In this table will explain any variable that used to calculate $Z$ value on equation 5 .

b. Initialisation chromosome

In initialisation step is process to establish a chromosome. It is a matrix of order $j *$ $k$, where $j$ is distribution centre $1 \ldots q$ and $k$ is customer $1 \ldots r$.

c. Evaluation chromosome

Calculate $Z$ value with equation 5

d. Sorting function

After we get the fitnes value, next the fitness values is called the best fitness. It is will compared with the best fitness previously.

e. Selection function

The aims of process selection is to keep the chromosome that own best fitness value, and will eliminated the chromosome that have bad fitness value. the fitness value on this step will converted using equation 10.

$$
n e w \_f i t(c)=e^{v^{*} f i t(c)}
$$

f. Crossover function

Crossover is a process to get a old chromosome, a chromosome that will crossover until produce the offspring.

g. Mutation function

In this step, mutation process have a main parameter, it is probabilitas mutation ( $\left.p \_m u t\right)$. This value will compare with $R$-mut that obtained randomly. If $R \_m u t<$ $p \_m u t$ so the mutation process will be execute.

h. Output

In the end step will showed the fitness value of chromosome that have optimal value. it's minimaze $Z$.

\section{$4 \quad$ Result and Analysis}

The result in this research will analyzed and showed in Tabel 2 . The data result produced using 15 data testing. This data is the cost distribution from plant to customer througt distribution center. After that, the next testing do with TORA software. This aims is we can know that the result which execute with GA is more accurate, or closed if calculate with TORA. 
Table 2. Percentage of Test Result.

\begin{tabular}{llllll}
\hline \multirow{2}{*}{ No } & \multirow{2}{*}{ Data } & \multicolumn{2}{c}{ Solution } & \multirow{2}{*}{ Different value } & Persentage (\%) \\
\cline { 3 - 4 } & & TORA & AG & & \\
\hline 1 & Data 1 & 237763.5 & 237750 & 13.5 & 0.005 \\
2 & Data 2 & 157055 & 157050 & 5 & 0.003 \\
3 & Data 3 & 161711.4 & 161880 & 168.6 & 0.104 \\
4 & Data 4 & 56022.5 & 56638 & 615.5 & 1.086 \\
5 & Data 5 & 64741.85 & 64743 & 1.15 & 0.001 \\
6 & Data 6 & 253413 & 254530 & 1117 & 0.438 \\
7 & Data 7 & 74652 & 74738 & 86 & 0.115 \\
8 & Data 8 & 73199 & 73195 & 4 & 0.005 \\
9 & Data 9 & 45467.3 & 47140 & 1672.7 & 3.548 \\
10 & Data 10 & 168826 & 169825 & 999 & 0.588 \\
11 & Data 11 & 52591.5 & 53997 & 1405.5 & 2.602 \\
12 & Data 12 & 132893.6 & 132890 & 3.6 & 0.002 \\
13 & Data 13 & 93105 & 97707 & 4602 & 4.71 \\
14 & Data 14 & 279513.5 & 279680 & 166.5 & 0.059 \\
15 & Data 15 & 71455.5 & 75293 & 3837.5 & 5.096 \\
\hline
\end{tabular}

The data in Table 2. describe that the result is accurate. The data from calculate using genetic algorithm with parameter such as : number of chromosome $=10$, crossover probability $=0.3$, mutasion probability $=0.5$ and number of generation $=p q+q$ r. According to this scenario the result using TORA on Data 1 is $=237763.5$ and using algorithm is $=237750$. The data 1 data 2 , data 8 , data 9 , and data 11 show that using genetic algorithm, the value of cost distribution more than minimize if using TORA.

\section{Conclusion}

The conclusion of this research is genetic algorithm can used to solve distribution problems. This algorithm is capable to get optimal solution, closed with TORA. This corresponds to the average percentage of difference value is $1.22 \%$. The performance of genetic algorithm is associated with any parameter such as : number of chromosome, crossover probablity and mutation probability. The number of chromosome can associated, if the number is too poor so the chromosome will reach convergence soon and the result value often at local optimal position. And the opposite, the number of chromosome is more so the calculation is more complex and the time computation is longer. 


\section{References}

[1] A. S. Yadav, A. Swami, G. Kher, and A. Garg, "Analysis of seven stages supply chain management in electronic component inventory optimization for warehouse with economic load dispatch using genetic algorithm," vol. 4, no. 2, pp. 18-29, 2017.

[2] T. İnkaya and M. Akansel, "Coordinated scheduling of the transfer lots in an assembly-type supply chain: a genetic algorithm approach," J. Intell. Manuf., vol. 28, no. 4, pp. 1005-1015, 2017.

[3] N. Jawahar and A. N. Balaji, A genetic algorithm for the two-stage supply chain distribution problem associated with a fixed charge, vol. 194, no. 2. Elsevier B.V., 2009.

[4] A. Diabat and R. Deskoores, "A hybrid genetic algorithm based heuristic for an integrated supply chain problem," J. Manuf. Syst., 2015.

[5] S. Validi, A solution method for a two-layer sustainable supply chain distribution model Original. 2015.

[6] H. A. Taha, “Operations Research An Introduction Eighth Edition.” p. 838, 2007.

[7] M. Gen and R. Cheng, "Books of Interest," 1997, p. 432.

[8] K. Sarrafha, S. H. A. Rahmati, S. T. A. Niaki, and A. Zaretalab, "A bi-objective integrated procurement, production, and distribution problem of a multi-echelon supply chain network design: A new tuned MOEA," Comput. Oper. Res., vol. 54, pp. 35-51, 2015. 